\title{
O QUE DIZEM OS EDUCANDOS SOBRE AS SUAS APRENDIZAGENS NO AVA MOODLE
}

\author{
Thiago Sávio Carbone ${ }^{1}$ (thiago.carbone@ bento.ifrs.edu.br) \\ Daniela Brun Menegotto² (daniela.menegotto@bento.ifrs.edu.br) \\ Profa. Dra. Eliane Schlemmer ${ }^{3}$ (elianes@ unisinos.br)
}

\section{RESUMO}

O artigo apresenta um estudo, que consta da análise dos registros que evidenciam as reflexões dos sujeitos, em relação as suas próprias aprendizagens no espaço denominado "Diário" disponível na disciplina "Ambientação no Moodle", turma iniciada no segundo semestre do ano de 2010, no AVA - Ambiente Virtual de Aprendizagem MOODLE - Modular Object-Oriented Dynamic Learning Environment, utilizado para o desenvolvimento do Curso Técnico em Informática - Formação de Instrutores, na modalidade a distância, do IFRS - Instituto Federal de Ciência e Tecnologia do Rio Grande do Sul - Campus Bento Gonçalves. O Curso tem como objetivo oportunizar a construção do conhecimento em diferentes áreas da informática e a aplicabilidade dos recursos tecnológicos no mercado de trabalho, além de contribuir para o desenvolvimento e qualificação do ensino de informática, através da inclusão no mercado, de profissionais qualificados, inovadores e capazes de transformar a realidade vivenciada. Partindo do princípio da liberdade e das características de flexibilidade e adaptabilidade, além da versatilidade proporcionada pela grande rede: a Internet, a análise dos dados coletados teve como fundamentação teórica os estudos das obras de Castells (2003) e Moraes (2003).

Palavra-Chave: Ambiente Virtual de Aprendizagem, MOODLE, Aprendizagem.

\section{ABSTRACT}

The article presents a study, which appears in those records that show the reflections of the subjects regarding their own learning space called "Diary" is available in the discipline "Environment in Moodle", class started in the second half of 2010, the VLE - Virtual Learning Environment MOODLE - Modular Object-Oriented Dynamic Learning Environment, used for the development of the Course in Computer Technician - Training of Instructors in the distance, the IFRS - Federal Institute of Science and Technology of Rio Grande do Sul - Campus Bento Gonçalves. The course aims to create opportunities to build knowledge in different areas of information technology resources and the applicability of the labor market, and contribute to the development and qualification of teaching computer science through the inclusion in the market, professionals, innovators and able to transform the lived reality. Based on the principle of freedom and the characteristics of flexibility and adaptability, and versatility provided by large network: the Internet, the data analysis had as theoretical studies of the works of Castells (2003) and Moraes (2003).

Keywords: Virtual Learning Environment, MOODLE, Learning. 


\section{LIBERDADE DE EXPRESSÃO: PRINCÍPIO ESSENCIAL PARA A ORGANIZAÇÃO DA SOCIEDADE EM REDE}

A Internet está fundamentada no princípio da liberdade. Portanto, de acordo com Castells (2003) a Internet é, acima de tudo, uma criação cultural ${ }^{4}$. Permite o desenvolvimento da autonomia e propicia a construção do conhecimento, uma vez que sujeitos de diferentes culturas, espalhados geograficamente, têm a possibilidade de compartilhar seus saberes por meio de diferentes Tecnologias Digitais Virtuais - TDVs. Assim, a Internet passou a ser a base tecnológica da Era da Informação: a rede.

A grande rede permite o uso de recursos tecnológicos digitais na área de educação que incentivam e convidam o sujeito para o desenvolvimento da autonomia, da autoria e da criatividade, possibilitando a transição para uma nova forma de organização de sociedade, a Sociedade em Rede, com características de flexibilidade e adaptabilidade, essenciais para viver, conviver e prosperar num mundo em rápida transformação. A flexibilidade da Internet permite aos sujeitos compartilhar suas idéias, os seus pensamentos e articulá-los por meio de ferramentas disponíveis, por exemplo, em ambientes virtuais de aprendizagem, tais como o MOODLE.

Levando em consideração que o princípio da criação da Internet está na promoção da liberdade na forma como o sujeito pensa, entendemos a mesma como sendo uma liberdade de expressão, permitindo aos sujeitos o desenvolvimento crítico do seu pensamento rumo a um pensamento complexo, que conforme Moraes (2003) "Pensar o complexo é ser capaz de unir conceitos divergentes e que normalmente são catalogados de maneira fechada e com visão limitada. É ter um pensamento capaz de pensar o contraditório, de analisar e sintetizar, de construir, desconstruir e reconstruir algo novo" (p. 199). Assim, o objetivo deste trabalho é analisar as reflexões dos educandos, que iniciam o Curso Técnico em Informática - Formação de Instrutores na modalidade a distância cursando o primeiro componente curricular denominado "Ambientação no MOODLE", em relação as suas próprias aprendizagens durante as interações ocorridas nos primeiros contatos no e com o AVA MOODLE, portanto, analisa-se a tomada de consciência dos educandos sobre o seu processo de aprendizagem no que tange a ambientação no AVA MOODLE.

Advindo da evolução tecnológica e baseado nos recursos disponíveis na Internet, compreendemos que todo e qualquer AVA é concebido tendo como pressupostos teóricos uma ou mais concepções de aprendizagem, uma vez que Costa e Franco (2005) nos auxiliam com a seguinte afirmativa "Toda inovação tecnológica em educação precisa se basear em um contexto epistemológico bem definido" (p. 1), ou seja, por uma crença sobre a origem do conhecimento, em outras palavras: de como um sujeito aprende.

Schlemmer (2005) vai além dizendo que no uso de um AVA, o primeiro e mais importante item a ser analisado é o critério didático-pedagógico do software, uma vez que todo e qualquer desenvolvimento de um produto para educação é permeado por uma concepção epistemológica, ou seja, por uma crença de como se dá à aquisição do conhecimento, de como o sujeito aprende. Essa concepção é a base do desenvolvimento dos processos de ensino e de aprendizagem, que é expresso nas ações educativas. 
Portanto, a forma como o docente age pedagogicamente pode reforçar ou mudar o contexto epistemológico que subjaz ao desenvolvimento tecnológico digital. Assim, uma prática pedagógica docente fundamentada em uma concepção_interacionista-construtivista tende a possibilitar o uso de diferentes espaços para os educandos expressarem o que pensam a respeito do próprio processo de aprendizagem. A disponibilidade para a escuta e a abertura para o diálogo são fatores fundamentais para o desencadeamento dos processos de aprendizagem. De acordo com Freire (2001), "Ensinar exige saber escutar" (p. 127), pois é escutando que aprendemos a falar com os outros, e, ao mesmo tempo "Ensinar exige disponibilidade para o diálogo" (p.152). Desta forma, oportunizar o diálogo possibilita a criação de vínculos afetivos entre todos os sujeitos que participam dos processos de ensino e de aprendizagem. De acordo com Becker (2003), o que faz uma ação efetivamente acontecer é a afetividade.

Portanto, um AVA pode possibilita a (re)significação do ensinar e do aprender, além de promover o desencadeamento de uma formação autônoma dos sujeitos envolvidos no processo educacional, permeando uma nova forma de organização, expressão, ação coletiva e construção de significados.

\section{O AVA MOODLE E OS DIFERENTES ESPAÇOS DE COMUNICAÇÃO, INTERAÇÃO E REFLEXÃO}

O AVA MOODLE - Modular Object-Oriented Dynamic Learning Environment é um software livre, de apoio ao desenvolvimento dos processos de ensino e de aprendizagem, executado por meio dos serviços disponíveis na Internet. A expressão remete então a um Sistema de Gestão da Aprendizagem baseado no desenvolvimento de trabalho colaborativo e cooperativo.

Tendo como pressupostos teóricos os princípios da pedagogia sócio-construtivista, conforme mencionado por Martin Dougiamas ${ }^{6}$, na área educacional o MOODLE constitui-se em um sistema que possibilita a gestão de cursos desenvolvidos por meio do uso da Internet. Desta forma as diferentes ferramentas disponíveis no AVA permitem aos docentes a organização didática on line da própria ação pedagógica.

A concepção epistemológica de construção do conhecimento que deu origem e sustenta o ambiente, convida o educando a ser sujeito ativo no processo de aprendizagem para a construção coletiva do conhecimento. O AVA MOODLE visa o desenvolvimento de grupos de trabalho, na qual participam os diferentes sujeitos da aprendizagem. Neste ambiente é possível descobrir novas formas de viver e conviver em grupos sustentado por relações de autonomia, colaboração e cooperação.

É importante que a metodologia para utilizar o AVA MOODLE seja baseada no pressuposto da atividade cooperativa, envolvendo diferentes espaços de comunicação e interação e possibilitando um processo de ação e de reflexão dos sujeitos da aprendizagem. Becker (2003), baseando-se nas idéias de Piaget: "Aprende-se porque se age e não porque se ensina" (p. 14). Portanto, para Piaget (1978) é a ação do sujeito que possibilita a construção do conhecimento, e esta ação, necessariamente, se constitui como uma ação mental. Assim, conforme BECKER (2003), a partir dos resultados da ação, o sujeito vai apropriando-se, progressivamente, dos mecanismos íntimos da ação própria, permitindo a tomada de consciência ${ }^{7}$. 
O pressuposto da atividade cooperativa inclui e incentiva a possibilidade de um trabalho em equipe, pois oportuniza o desenvolvimento do pensamento e da autonomia através de trocas intelectuais, sociais, culturais e políticas, favorecendo a tomada de consciência. Segundo Becker (2003), a tomada de consciência é um processo que ocorre conforme o sujeito vai se dando conta, de como age, tornando-se capaz de reproduzir sua própria ação, corrigindo seus rumos, eliminando trajetos desnecessários ou criando trajetos novos, dirigindo-se para novos objetivos. Desta forma, a tomada de consciência é parte do processo de construção de conhecimento.

A metodologia deste ambiente virtual de aprendizagem, implica num processo de comunicação descentralizado e heterárquico, porém mediado em praticamente todas as funções interativas possíveis no espaço do ambiente. Desta forma, procura oferecer instrumentos efetivos para uma multiplicidade de significações que se originam a partir dos esquemas ${ }^{8}$ dos sujeitos.

Vejamos a seguir, por meio da Tabela 1, algumas das diferentes ferramentas disponíveis no AVA MOODLE que permitem a sistematização do fazer pedagógico docente visando o desencadeamento dos processos de comunicação e de interação. As ferramentas foram agrupadas por categorias, de acordo com as suas funcionalidades:

\begin{tabular}{|c|c|}
\hline CATEGORIA & FERRAMENTA \\
\hline $\begin{array}{l}\text { Organização de } \\
\text { Informações } \\
\text { Pessoais }\end{array}$ & $\begin{array}{l}\text { • Perfil } \\
\text { Ferramenta que possibilita o sujeito a se apresentar para todos os } \\
\text { participantes. } \\
\text { • Blog } \\
\text { Espaço que possibilita o usuário criar o seu espaço de informações } \\
\text { pessoais, sites e arquivos, via upload. Estas informações podem } \\
\text { ser pessoais ou ainda compartilhadas com os demais participantes. }\end{array}$ \\
\hline $\begin{array}{l}\text { Compartilhamento } \\
\text { de Informações }\end{array}$ & $\begin{array}{l}\text { • Rótulo } \\
\text { Espaço para registrar orientações gerais para os participantes. } \\
\text { • Envio de arquivo único } \\
\text { Espaço para o upload de arquivos que serão acessados pelo } \\
\text { docente. Nele o docente pode registrar o feedback das atividades } \\
\text { propostas e realizar a avaliação das mesmas. } \\
\text { • Glossário } \\
\text { Espaço para a criação de um glossário compartilhado, organizado } \\
\text { em ordem alfabética permite o desenvolvimento de diferentes } \\
\text { conceitos. } \\
\text { • Base de dados } \\
\text { Espaço para o upload de arquivos que serão acessados e utilizados } \\
\text { coletivamente. }\end{array}$ \\
\hline Comunicação & $\begin{array}{l}\text { • Fórum de notícias } \\
\text { Espaço para recados informais, avisos e convites sociais. } \\
\text { • Correio } \\
\text { Através do correio eletrônico, os alunos podem trocar informações } \\
\text { com os professores, de forma individual. } \\
\text { • Diário } \\
\text { Espaço individual para o registro das percepções e reflexões. Este } \\
\text { espaço possibilita a comunicação entre docente e discente. }\end{array}$ \\
\hline
\end{tabular}




\begin{tabular}{|c|c|}
\hline CATEGORIA & \multicolumn{1}{|c|}{ FERRAMENTA } \\
\hline & $\begin{array}{c}|c| \\
\text { Espórum } \\
\text { para promover as discussões. } \\
\bullet \quad \text { Chat } \\
\text { Espaço para a realização de encontros virtuais síncronos } \\
\text { previamente agendados pelo docente. }\end{array}$ \\
\hline
\end{tabular}

Tabela 1 - Principais ferramentas interativas do AVA MOODLE

Portanto, o AVA MOODLE é um ambiente que disponibiliza ferramentas que proporcionam a comunicação e a interatividade entre os sujeitos e com o próprio ambiente, para a construção do conhecimento. Não é o objetivo, deste estudo, aprofundar cada um dos espaços de interação, que com certeza, merecem ser contemplados e analisados profundamente.

Porém, é importante ressaltar que o AVA MOODLE, por meio do espaço "Diário" possibilita a realização dos registros das reflexões sobre as próprias ações dos sujeitos que participam do ambiente, e conseqüentemente abre espaço para os mesmos expressarem de forma escrita as suas percepções em relação ao processo de aprendizagem, atendendo o objetivo deste estudo conforme anunciado no início do texto.

É com base nos registros sistematizados realizados no espaço "Diário" que evidenciamos e analisamos a seguir o que dizem os educandos do IFRS - Campus Bento Gonçalves, sobre as suas aprendizagens no AVA MOODLE quando iniciam o primeiro componente curricular denominado “Ambientação no MOODLE” do Curso Técnico em Informática - Formação de Instrutores na modalidade a distância.

O docente do referido componente curricular organizou didaticamente o seguinte espaço no componente curricular "Ambientação no MOODLE":

\section{REFLEXÕES SOBRE AS PRÓPRIAS APRENDIZAGENS ON LINE...}

\section{Reflexões sobre as aprendizagens no AVA MOODLE}

Figura 1 - Espaço para o registro das reflexões dos educandos

Ao clicar sobre o link "Reflexões sobre as aprendizagens no AVA MOODLE", visível na Figura 1, o educando encontra a seguinte proposta de trabalho:

\section{Ambientação no Moodle - 40 horas presenciais}

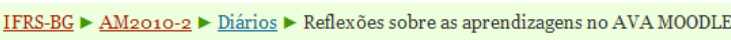

Utilize este espaço para registrar as suas percepções em relação às aprendizagens por meio do uso do AVA MOODLE.

Você acredita que este ambiente virtual vem possibilitando o desenvolvimento da sua aprendizagem? De que forma?

Figura 2 - Proposta de trabalho para o registro das reflexões 
Os extratos coletados por meio do espaço "Diário", conforme proposta de trabalho acima, evidenciam as diferentes tomadas de consciência dos educandos em relação ao próprio processo de aprendizagem por meio do AVA MOODLE, permitindo perceber as categorias que se originam da teoria que fundamenta este estudo:

\section{- Adaptação no uso do AVA}

Um educando escreve: "Bom, ainda está bastante complicado pra mim, pois minha experiência na área da informática é pouca, mas a cada semana que passa estou me sentindo mais confiante".

O extrato acima mostra a tomada de consciência do educando em relação a pouca prática em relação ao manuseio das ferramentas da informática, como também faz referência ao processo de aprendizagem do aluno em relação a sua adaptação no curso na modalidade a distância e apropriação do ambiente virtual, uma vez que afirma que a cada semana que passa vai se sentindo mais confiante em relação ao uso do AVA.

Acreditamos que a confiança seja um elemento desencadeador do processo de acomodação, que conforme Piaget (1976) é quando o sujeito se modifica para poder conhecer o objeto no qual interage, neste caso específico, o ambiente virtual.

Outro educando refere: "Acredito que o ambiente facilite muito no sentido de acesso as informações, como agora estamos iniciando mais disciplinas, o que inicialmente parecia confuso, acaba ficando bem organizado e fácil de nos acharmos".

O processo de adaptação também pode ser percebido no registro acima quando o educando refere: “...o que inicialmente parecia confuso, acaba ficando bem organizado e fácil de nos acharmos". Conforme Franco (1998) "Adaptação é um processo pelo qual o ser vivo consegue garantir sua vida no meio em que se encontra" (p. 34).

\section{- Desenvolvimento da autonomia}

Nesta categoria encontramos evidências da importância de ser autônomo e/ou a necessidade de desenvolver autonomia durante o processo de aprendizagem, a partir dos registros que seguem: "Acredito que vem possibilitando o desenvolvimento de minha aprendizagem, pois quando entramos no MOODLE, temos que estar dispostos a buscar as atividades, tarefas e os textos e dedicar essa busca à realização do que foi proposto". "Posso dizer que a melhor forma de conhecer um ambiente novo, é "clicando" em tudo, dessa maneira nos acostumamos com o ambiente, e quando vejo que me perdi, volto desde a página inicial e recomeço".

Desta forma, o extrato "...quando entramos no MOODLE, temos que estar dispostos a buscar as atividades..." e o extrato "... a melhor forma de conhecer um ambiente novo, é "clicando" em tudo..." expressam a necessidade de ser autônomo enquanto sujeito da própria aprendizagem. Segundo Schlemmer (2005), um sujeito é autônomo quando é capaz de especificar e analisar o que é adequado para ele. Menegotto (2006) complementa dizendo que um sujeito tem mais autonomia quanto mais ele possui capacidade de reconhecer suas necessidades de estudo, selecionando conteúdos, buscando e utilizando os materiais necessários, bem como organizando e avaliando o próprio processo de aprendizagem.

\section{- (Re)organização do tempo e do espaço}


Os extratos a seguir exibem a necessidade e a dificuldade dos educandos em relação a organização do tempo e do espaço: “...alguma dificuldade em delimitar os horários para os acessos aos conteúdos e realização das atividades propostas". "Precisa se organizar para cumprir os prazos....

Percebemos por meio destes registros que o fato do sujeito estar inserido no processo de ensino e de aprendizagem on line, e este ser flexível em relação ao tempo e espaço, requer do mesmo uma (re)organização destes dois elementos para propiciar o desencadeamento as ações que possibilitam o desenvolvimento de aprendizagem. Becker (1995) diz que um sujeito é construído passo a passo, a partir da ação própria, ação no espaço e no tempo.

\section{- Processo de Interação}

Alguns registros evidenciam a importância e a necessidade do processo de interação para o desenvolvimento do processo de aprendizagem por meio do uso do MOODLE.

"Adorei conhecer o AVA MOODLE... é uma maneira maravilhosa de estudar $e$ interagir...". Este trecho evidencia a interação como um novo e diferente elemento existente no processo educacional on line. Conforme Schlemmer (2005), a Internet pode proporcionar ao processo educacional grande poder de interação. Desta forma, a interação é compreendida como um conjunto de relações estabelecidas entre os sujeitos e o meio, num processo contínuo, consistindo num sistema de trocas, flexível.

“Achei excelente (o MOODLE), pois é prático e ágil, a interação com todos é dinâmica e o visual com tarefas e conteúdos em destaque facilita muito para encontrarmos tudo de forma rápida". Aqui o educando evidencia a dinamicidade no processo de interatividade, expressando o movimento existente no processo de aprendizagem.

"As formas que me ajudaram na aprendizagem foram: leituras, pesquisa, interação com colegas, tutores e professores, reflexão e até mesmo com o erro, que foi construtivo para minha aprendizagem". Este registro nos leva a acreditar na aprendizagem como processo de interação, na relação com o outro e com o meio.

\section{- Cultura virtual de aprendizagem}

O extrato abaixo nos permite perceber, dentre outros fatores, que a mudança no meio, em que se desenvolve o processo educacional, desencadeia nos sujeitos uma nova cultura em relação as formas de aprender: "Com certeza o ambiente virtual vem possiblitando a minha aprendizagem, inserindo uma cultura de rede na qual, estou comprometida na minha formação e de meus colegas, parece ser um desafio lançado, a educação pela possibilidade de aprendizagem, transmitir $e$ produzir conhecimentos de maneira cooperativa em atividade cotidiana, usando o ambiente virtual de aprendizagem. A criação do ambientes virtuais tbm me traz benefícios que me permitem a convivência, a interligação de saberes, a troca de experiências, que pode ser um caminho na formação profissional, possibilitando um espaço para discussões, interação e comunicação na forma reflexiva. Esses novos espaços de experiência e de vivência certamente terão impacto no modo como aprendemos. "Assim, de acordo com Castells (2003), a Internet é uma criação cultural, compreendida como uma construção coletiva que transcende preferências individuais e influencia o pensamento e a ação dos sujeitos envolvidos. A flexibilidade da Internet, como meio para o desenvolvimento do processo educacional, permite aos sujeitos compartilhar suas idéias, os seus pensamentos e articulá-los por meio dos diferentes espaços disponíveis no ambiente virtual. 
Analisando os registros dos sujeitos, na ferramenta Diário, percebemos que os mesmos foram ao encontro da proposta pedagógica inicial, que tinha como o intuito promover a reflexão sobre as próprias ações dos educandos, em relação as suas aprendizagens no AVA MOODLE, possibilitando processos de tomadas de consciência, buscando o desenvolvimento cognitivo e como consequiência disto a construção de novas aprendizagens.

\section{CONSIDERAÇÕES FINAIS}

As Tecnologias Digitais vem transformando o mundo e a sociedade atual. Porém, as mesmas também são transformadas na medida em que a sociedade as utiliza. Portanto, há necessidade da ocorrência de mudanças culturais paradigmáticas. É fundamental a mudança no movimento do pensamento: da linearidade para a não-linearidade, do estático para o dinâmico, da unilateralidade para a dialeticidade.

Os AVAs constituem, juntamente com outras tecnologias digitais, a possibilidade de novas formas de organização social, e dão origem ao desenvolvimento de uma cultura virtual de aprendizagem. Desta forma, abrem-se novas possibilidades educacionais promotoras dos processos de interação. Assim, estes ambientes permitem que todos os sujeitos interajam com as idéias dos outros, desenvolvendo o senso crítico, o pensar sobre o seu próprio pensar e sobre o pensar do outro, promovendo o processo de reflexão e de tomada de consciência.

Quando do primeiro contato com o AVA os sujeitos sentem necessidade de um período de adaptação, diante das diferentes possibilidades educacionais vislumbradas, configurando assim um processo de aprendizagem em relação ao próprio uso dessa tecnologia digital.

Para interagir no e com o AVA há necessidade de uma (re)organização de tempo e de espaço para propiciar o desencadeamento das ações que possibilitam o desenvolvimento de aprendizagem nos sujeitos.

Ainda, no ambiente virtual de aprendizagem os educandos são sujeitos da própria aprendizagem, o que exige dos mesmos o desenvolvimento da autonomia.

O AVA MOODLE oferece diferentes espaços educacionais propulsores do desenvolvimento de um pensamento complexo, ou seja, no conflito, na diferença e na contradição é que encontramos o movimento necessário para a construção do conhecimento. Porém, o ambiente somente, não é suficiente para que mudanças na área da educação ocorram. Os sujeitos do processo de ensino e de aprendizagem também necessitam mudar.

\footnotetext{
${ }^{1}$ Doutorando em Educação - Programa de Pós-graduação em Educação - UNISINOS - Universidade do Vale do Rio dos Sinos. Mestre em Ciências da Computação - Universidade Federal de Pernambuco. Docente do Instituto Federal do Rio Grande do Sul - IFRS - Campus Bento Gonçalves.
} 
2 Doutoranda em Informática na Educação - PGIE - Programa de Pós-graduação em Informática na Educação - UFRGS - Universidade Federal do Rio Grande do Sul. Mestre em Educação - PGEDU - Programa de Pós-graduação em Educação - UNISINOS - Universidade do Vale do Rio dos Sinos. Docente do Instituto Federal do Rio Grande do Sul - IFRS - Campus Bento Gonçalves.

${ }^{3}$ Doutora em Informática na Educação - UFRGS - Universidade Federal do Rio Grande do Sul. Mestre em Psicologia do Desenvolvimento -

UFRGS - Universidade Federal do Rio Grande do Sul. Professora e Pesquisadora do Programa de Pós-Graduação em Educação da Universidade do Vale do Rio dos Sinos - UNISINOS.

${ }^{4}$ Construção coletiva que transcende preferências individuais e influencia o pensamento e as práticas dos sujeitos envolvidos.

${ }^{5}$ Este componente curricular tem por objetivo permitir ao educando conhecer e interagir com as ferramentas disponíveis no AVA, reconhecendo-as como diferentes e possíveis espaços de convivência para a construção coletiva do conhecimento e possibilidade de desenvolvimento da aprendizagem.

${ }^{6}$ Educador e cientista computacional que idealizou o MOODLE no ano de 2001.

${ }^{7}$ Segundo Piaget (1978), é a reflexão sobre a ação que permite o desencadeamento do processo de tomada de consciência no sujeito.

${ }^{8}$ De acordo com Piaget (1976), compreendemos os esquemas como sendo as organizações já construídas pelo sujeito em nível de pensamento.

\section{REFERÊNCIAS BIBLIOGRÁFICAS}

BECKER, Fernando. Epistemologia do Professor. O Cotidiano da Escola. Petrópolis, RJ: Vozes, 1995.

BECKER, Fernando. A Origem do Conhecimento e a Aprendizagem Escolar. Porto Alegre: Artmed, 2003.

CASTELLS, Manuel. A Galáxia da Internet. Reflexões sobre a Internet, os Negócios e a Sociedade. Rio de Janeiro: Jorge Zahar e., 2003.

COSTA, Luciano A. C. da; FRANCO, Sérgio Roberto Kieling. Ambientes Virtuais de Aprendizagem e suas Possibilidades Construtivistas. PGIE - UFRGS. Informática na Educação: Teoria \& Prática. V. 3, $\mathrm{N}^{0}$ 1, Maio, 2005. Disponível em:

<http://www.cinted.ufrgs.br/renote/maio2005/artigos/a25_ambientesvirtuais.pdf> Acesso em: outubro de 2009.

FRANCO, Sergio Roberto Kieling. O Construtivismo e a Educação. $8^{a}$ edição. Porto Alegre, Mediação, 1998.

FREIRE, Paulo. Pedagogia da Autonomia. Saberes Necessários à Prática Educativa. $18^{\mathrm{a}}$ Edição. Rio de Janeiro: Paz e Terra, 2001.

MENEGOTTO, Daniela Brun. PRÁticAs PEDAGógiCAS ON LINE: os processos de ensinar e de aprender utilizando o AVA-UNISINOS. São Leopoldo: UNISINOS, 2006. Dissertação (Mestrado em Educação) Programa de Pós-Graduação em Educação, Universidade do Vale do Rio dos Sinos, 2006.

MORAES, Maria Cândida. Educar na Biologia do Amor e da Solidariedade. Petrópolis, RJ: Vozes, 2003.

PIAGET, Jean. A Equilibração das Estruturas Cognitivas - Problema Central do Desenvolvimento. Zahar Editores. Rio de Janeiro, 1976. 
PIAGET, Jean. A Tomada de Consciência. São Paulo: Melhoramentos, 1978.

SCHLEMMER, Eliane. Metodologias para Educação a Distância no Contexto da Formação de Comunidades Virtuais de Aprendizagem. In: Rommel Melgaço Barbosa. (Org.). Ambientes Virtuais de Aprendizagem. Porto Alegre: Artmed Editora, 2005, v. , p. 29-49.

SCHLEMMER, Eliane. "A Formação do Educador na Interação com o AVA em Mundos Virtuais: Percepções e representações". Projeto de Pesquisa. Programa de Pós-Graduação em Educação - Unisinos. São Leopoldo, 2005. 